\title{
Sensorless Control of BLDC Motor using Flux Linkage Based Algorithm
}

\author{
Rajesh Nalli, K.Subbarao, M.Ramamoorthy, M.Kiran kumar
}

\begin{abstract}
The performance of Conventional sensorless back-emf detection techniques for BLDC Motor is poor at low speeds, since at zero and low speeds the magnitude of back-emf is very less. This causes failure of zero crossing instant detection. This paper presents a new Sensorless Control Technique for $B L D C$ motor drive to estimate the rotor position accurately even at zero and low speeds. A new algorithm has been developed to estimate the rotor position based on the prediction of stator flux linkages. The main advantage of the proposed technique is that the flux linkages are independent of the speed. For starting of the motor an open loop starting method was adopted. By implementing this technique the Meta heuristic digital signal control systems like PWM/ADC, PLL are avoided in order to make motor control easy and economical. To verify the accuracy of the proposed technique it is compared with existing hall sensors controlled BLDC drive operation. The validity of proposed scheme is verified through Simulation.
\end{abstract}

Index Terms: Sensorless technique - BLDC motor - hall effect sensors - shaft encoders - fluxlinkage algorithem.

\section{INTRODUCTION}

BLDC motor has become one of the better choices for many industrial applications, agricultural applications and hybrid electric vehicles etc. BLDC motors have several advantages like high power density, high torque to weight ratio and high efficiency compared with other motors. Compared to conventional DC motors, the commutation of BLDC motor is done by electronic process which depends on the rotor position. In general the rotor position of BLDCM estimation can be done by using sensor and sensorless methods. In sensor controlled technique the position of rotor can be estimated by using Hall Effect sensors or shaft encoders. The Hall Effect sensors will work based on electromagnetic property. The sensor based BLDC motor has a limitation that the controller does not get accurate sensing signal under severe environment conditions like in mining, petroleum and metallurgical industries which may lead to wrong prediction of rotor position. Alternately, the sensorless techniques provide the reduction of complexity, robustness of sensing equipment and overall cost of the drive [1].

Revised Manuscript Received on October 30, 2019.

* Correspondence Author

Rajesh Nalli*, Research Scholar,EEE Dept. Koneru Lakshmaiah Education Foundation Guntur, India

K.Subbarao, Prof. EEE Dept. Koneru Lakshmaiah Education Foundation Guntur, India

M.Ramamoorty, Former Chancellor, Koneru Lakshmaiah Education Foundation Guntur, India

M.Kiran Kumar, Asso.Prof. EEE Dept.Koneru Lakshmaiah Education Foundation Guntur, India

(C) The Authors. Published by Blue Eyes Intelligence Engineering and Sciences Publication (BEIESP). This is an open access article under the CC BY-NC-ND license (http://creativecommons.org/licenses/by-nc-nd/4.0/)

Sensorless methods are primarily classified as back-emf detecting, back-emf integrating, third harmonic integration and Freewheeling diode conduction duration methods [1][2]. The back Emf detecting relies on zero crossing detection of floating phase back emf waveform. The zero crossing instant is obtained by comparing it with virtual neutral point voltage. This method suffers from high frequency noise and the unstable neutral point voltage caused by PWM switching. So to minimise this effect low pass filters are used. The phase commutation position information can also be extracted by integrating unexcited phase emf [4]. The integration starts from zero crossing point of the back emf and stops when a threshold set value is reached. This method does not work properly for low speeds. In a star connected BLDC motor the commutation instants can be estimated from integrating the third harmonics voltages generated in the phases. This is expressed as

$$
\lambda_{\mathrm{r} 3}=\int V_{S U M} \cdot \mathrm{dt}
$$

Where

$\lambda r 3=$ rotor flux third harmonic component

$V_{S U M}=$ Summation of the stator phase voltages

$V_{S U M}=V_{A N}+V_{B N}+V_{C N}\left(e_{a}+e_{b}+\right.$

$\left.e_{c}\right) 3 . E_{3} \cdot \sin \left(3 . e \omega_{e} \cdot t\right)$

To obtain switching instants, the filtered voltage signal which provides the third harmonic voltage component is integrated to estimate the rotor flux linkage.

During freewheeling diode conduction, the open phase current flows through diodes for a short period of time. At the zero crossing point of the back emf of this phase, the diode current will become zero and Commutation of the phase takes place at this instant. This method works for low speeds and the drawback of this method is it requires six extra voltage sources [3]. Gui-Jia Su proposed rotor position estimation by filtering one of the motor terminal voltages [5]. By this method the number of components usage will be reduced. In [7] field oriented controlled BLDC motor drive using stator flux estimation technique with adaptive PI controller is proposed. A sensor less position detection based on speed independent position function $G(\theta)$ is derived in [8]. But this method incorporates many complex variables. Nobuyuki Matsui proposed sensor less operation based on difference between detected and estimated state variables [9]. In [10] wook-jin lee, seung-ki sul proposed a new Starting method for the BLDC motor using stator inductance variation based on rotor magnetic flux Baratieri proposed an I-F starting method for BLDC drive [11]. Sensor less back emf detection based on virtual neutral voltage, PLL controller and third harmonic voltage detection methods are proposed in [12] \& [13]. 
In this paper the sensor less control of BLDC motor has been proposed based on three phase flux linkages with open loop starting method. This method overcomes the drawback of all back emf detection based sensorless techniques. Compared with back emf detection method, the flux linkage based algorithm has speed independent function so this method gives consistent rotor position information independent of speed. The proposed control technique is developed in MATLAB / Simulink to validate its performance. The motor performance with the proposed controller is compared with existing Hall Effect sensor based control method.

\section{BRUSHLESS DC MOTOR MODEL}

A 3- $\phi$, 4 pole star connected BLDC motor has been considered with permanent magnets on the rotor. The terminology used in the mathematical modelling equations is given below.

$V_{a c}, V_{b c}, V_{b a}=$ phase to phase voltages,

$I_{a}, I_{b}, I_{c}=$ line currents,

$R_{a}=R_{b}=R_{c}=\mathrm{R}=$ winding resistances in ohm's,

$L_{a s}, L_{b s}, L_{c s}=$ self-inductance of each phases in henry,

$L_{m}=$ mutual inductance between phases,

$e_{a c}, e_{b c}, e_{b a}=$ the phase to phase back emf's.

$L_{a s}+L_{m}=L$ Where $L$ represents phase inductance under balanced condition.

The modelling equations of BLDC motor are given as

Phase voltages:

$$
\left.\begin{array}{l}
V_{a}=i_{a} R+L \frac{d i_{a}}{d t}+e_{a} \\
V_{b}=i_{b} R+L \frac{d i_{b}}{d t}+e_{b} \\
V_{c}=i_{c} R+L \frac{d i_{c}}{d t}+e_{c}
\end{array}\right\}
$$

Phase back emf's are described as.

$$
\begin{aligned}
& e_{a}=K_{e} \cdot f\left(\theta_{a}\right) \cdot \omega \\
& e_{b}=K_{e} \cdot f\left(\theta_{b}\right) \cdot \omega \\
& e_{c}=K_{e} \cdot f\left(\theta_{c}\right) \cdot \omega
\end{aligned}
$$

Under balanced condition the resistance of all phases are equal and the Mutual inductance is constant. The phase to phase voltage equations are expressed in (4) \& (5).

$V_{a c}=\mathrm{R}\left(i_{a}-i_{c}\right)+\mathrm{Ld}\left(i_{a}-i_{c}\right) / \mathrm{dt}+e_{a c}$

$V_{c b}=\mathrm{R}\left(i_{c}-i_{b}\right)+\mathrm{Ld}\left(i_{c}-i_{b}\right) / \mathrm{dt}+e_{c b}$

In balanced condition, using KCL the sum of currents at a node is zero i.e.

$i_{a}+i_{b}+i_{c}=0$

$i_{c}=-i_{a}-i_{b}$

The phase currents $i_{a} \& i_{b}$ can be solved using equations (4), (5) \& (11) are given as

$$
\begin{gathered}
i_{a}=\int \frac{2}{3 L} V_{a c}+\frac{1}{3 L} V_{c b}-\frac{1}{L} i_{a} R-\frac{2}{3 L} e_{a c}-\frac{1}{3 L} e_{c b} \\
i_{b}=\int-\frac{1}{3 L} V_{a c}-\frac{2}{3 L} V_{c b}-\frac{1}{L} i_{b} R+\frac{1}{3 L} e_{a c}+\frac{2}{3 L} e_{c b}
\end{gathered}
$$

The electromagnetic Torque expression is given in equation (14)

$$
T_{e}=k_{t}\left[\left(f\left(\theta_{a}\right) I_{a}\right)+\left(f\left(\theta_{b}\right) I_{b}\right)+\left(f\left(\theta_{c}\right) I_{c}\right)\right]
$$

Where $k_{t}$ is torque constant

The first order mechanical modelling equation can be written as

$$
\mathrm{J} \frac{\mathrm{d} \omega_{\mathrm{m}}}{\mathrm{dt}}+\mathrm{B} \omega_{\mathrm{m}}=\mathrm{T}_{\mathrm{e}}-\mathrm{T}_{\mathrm{L}}
$$

Where $T_{L}=$ Load torque, $\mathrm{J}=$ moment of inertia, $\mathrm{B}=$ damping ratio of the motor.

From equation (15) the Rotor angular speed equation is derived as

$$
\omega_{\mathrm{r}}=\frac{\mathrm{T}_{\mathrm{e}}-\mathrm{T}_{\mathrm{L}}}{\mathrm{Js}+\mathrm{B}}
$$

\section{ANALYSIS OF PROPOSED SENSORLESS TECHNIQUE FOR BLDC MOTOR.}

BLDC motor consists of a 3-phase star connected concentrated winding on stator and a permanent magnet rotor. The commutation was performed by the static electronic switches from stator side. Figure. 1 shows the block diagram of 3-phase BLDC motor.

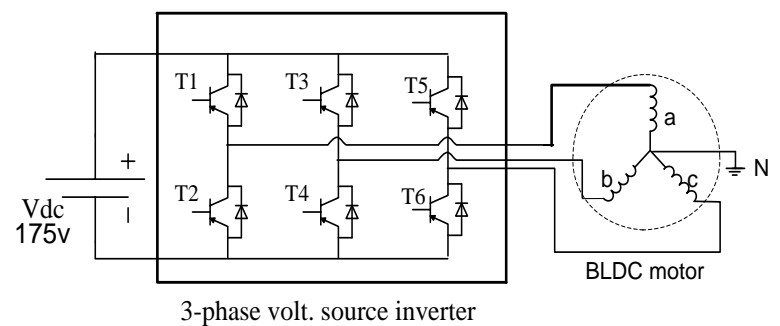

Figure.1 Blockdiagram of 3-phase BLDC motor with voltage source inverter.

A 3- $\phi$, 3-leg inverter operating with $120^{\circ}$ conduction mode is connected to stator of BLDC motor. During the operation, in each instant two phase windings are connected to inverter; hence voltage across the each phase winding is $V_{d c} / 2$. In BLDCM the Quasi square wave currents are generated in order to get constant torque as derived in modelling equations $(12,13)$. The amplitudes of these quasi square wave currents are limited to the desired reference current value which is proportional to the load torque.Figure. 2 shows the theoretical wave forms of 3-phase back emf, phase voltages and phase currents for the proposed method. 


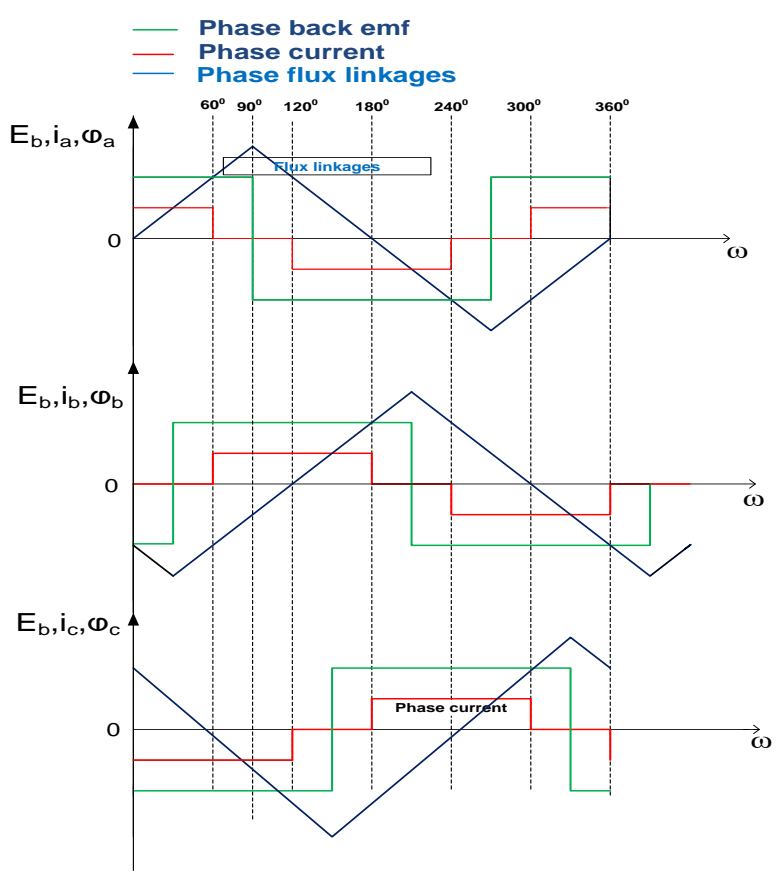

Figure.2

III.(a) Conduction sequences of proposed method

Stator phase currents of the BLDCM are controlled by the sequential triggering of inverter switches $T_{1}$ to $T_{6}$. Here the initial switching sequence can be estimated from the knowledge of rotor pole to stator pole alignment. In order to bring this alignment an open loop starting method is adopted. In the proposed method b, c phases are excited initially which brings the rotor quadrature axis in alignment with the phase a axis. The running switching sequence is estimated from the knowledge of the 3- $\phi$ flux linkages generated in the motor. As can be seen from Fig. 2 the commutations take place when one of the phase flux linkages go to zero. For example phase a is turned off when phase c flux linkage goes to zero. In running condition $\mathrm{AC}, \mathrm{BC}, \mathrm{BA}$ Phases are excited one after other. Two phase conduction mode is assumed for the motor operation. In the proposed method the sequence of switching operations are taken as 1-6, 3-6, 3-2, 5-2, 5-4, 1-4, and the corresponding applied voltages are $V_{a c}, V_{b c}, V_{b a}, V_{c a}, V_{c b}, V_{a b}$. Conduction path for first switching is $+V_{d c}-T_{1}-\mathrm{a}-\mathrm{c}-T_{6}-V_{d c}$ as shown in fig.4(a) and it's freewheeling path for phase $b$ is b- $D_{3}-T_{1}$-a which is shown in 4(a'). Figure. 3 shows the both conduction and freewheeling current paths. The magnitudes of each phase currents $i_{a}, i_{b}$ and $i_{c}$ for the first switching state (during $T_{1}, T_{6}$ switches $\mathrm{ON}$ ) are derived in equations (17) to (21). Similarly the phase current values for the other switching states are given in table1. Their conduction and freewheeling current paths of each phase are individually shown in figs.4(a) to 4(f').

During A, C phases conducting:

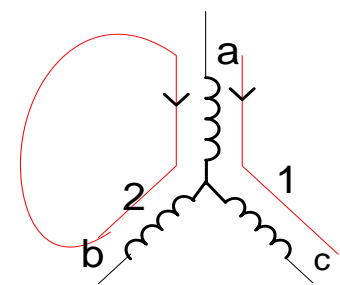

Figure.3

$$
\left.\begin{array}{c}
V_{d c}-i_{1} 2 \mathrm{R}-2 i_{1} \mathrm{Ls}-e_{a}-e_{c}=0 \\
i_{1}=V_{d c}-e_{a}-\frac{e_{c}}{2(\mathrm{R}+\mathrm{Ls})}
\end{array}\right\}
$$

Freewheeling path (2):

$$
\left.\begin{array}{c}
i_{2} 2 \mathrm{R}-2 i_{2} \mathrm{Ls}+e_{b}+e_{a}=0 \\
i_{2}=-\left(e_{b}+e_{a}\right) / 2(\mathrm{R}+\mathrm{Ls}) \\
i_{a}=i_{1}+i_{2} \\
i_{b}=i_{2} \\
i_{c}=i_{1}
\end{array}\right\}
$$

In the above equations ' $s$ ' is the Laplace operator. Conducting and freewheeling paths of various switching states:

Phase A, C conduction

(Switches 1, 6 are ON)

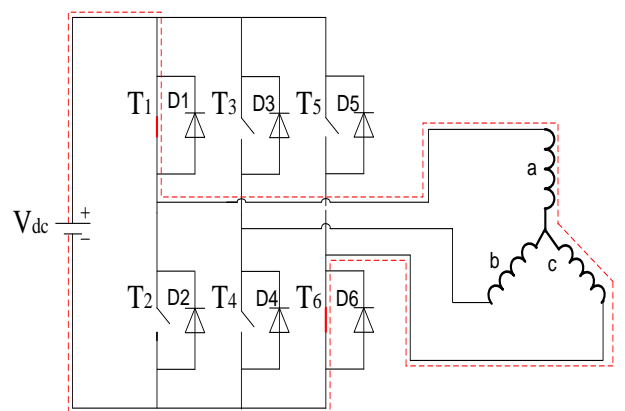

Figure.4 (a)

free wheeling

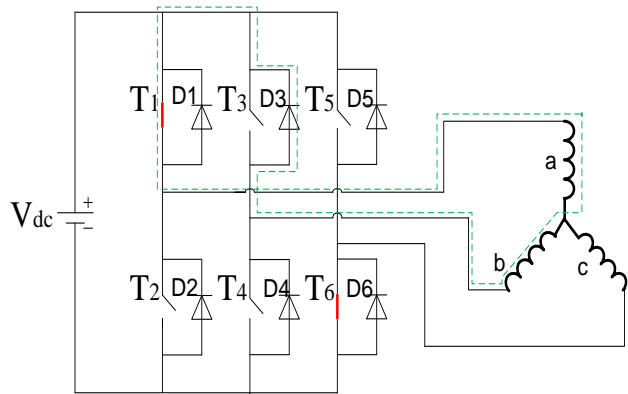

Figure.4 (a')

Phase $\mathrm{B}, \mathrm{C}$ conduction

(Switches 3, 6 are ON)

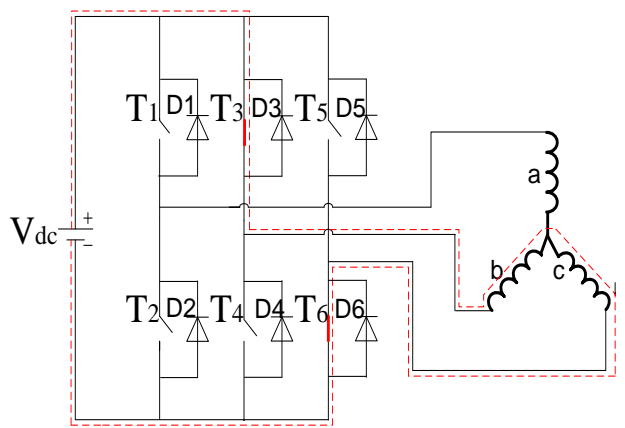

Figure.4 (b)

free wheeling

Conduction path (1): 


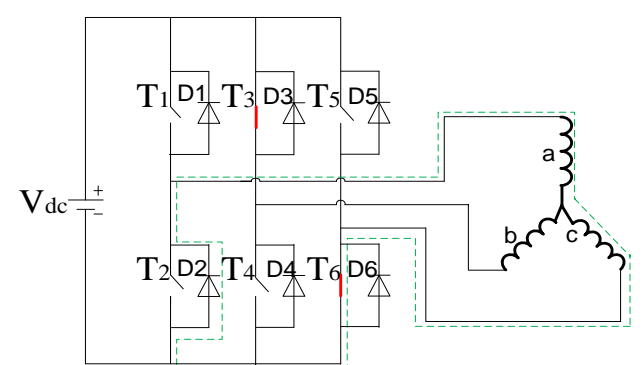

Figure.4 (b')

Phase $\mathrm{B}, \mathrm{A}$ conduction

(Switches 3, 2 are ON)

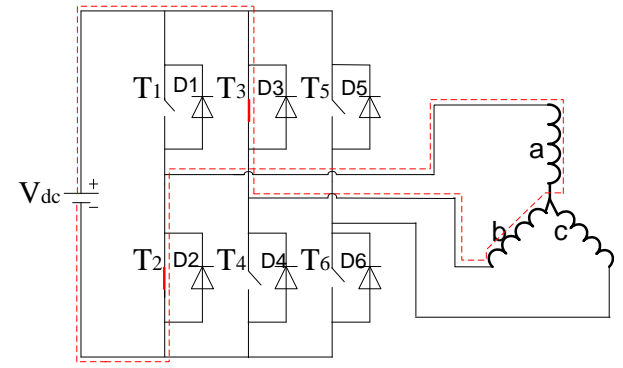

free wheeling

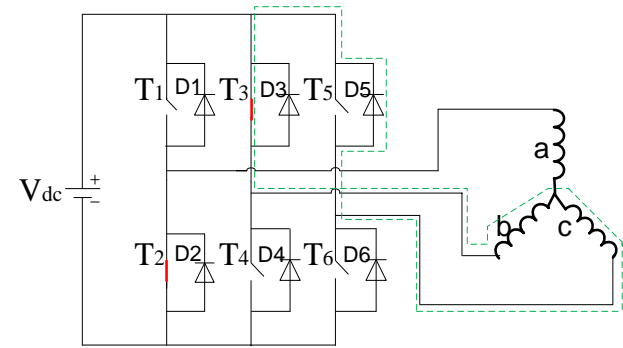

Figure.4 (c')

Phase currents under different switching states are given in

Table-1.

Table-1 Phase currents at various switching states

\begin{tabular}{|c|c|c|c|c|}
\hline $\begin{array}{c}\text { Con } \\
\text { ducti } \\
\text { ng } \\
\text { phas } \\
\text { es }\end{array}$ & $\begin{array}{l}\text { line } \\
\text { volta } \\
\text { ge }\end{array}$ & $\begin{array}{l}\text { Current } \\
\text { passing } \\
\text { through } \\
\text { Phase A }\end{array}$ & $\begin{array}{c}\text { Current } \\
\text { passing through } \\
\text { Phase B }\end{array}$ & $\begin{array}{c}\text { Current } \\
\text { passing through } \\
\text { Phase C }\end{array}$ \\
\hline $\mathrm{A}, \mathrm{C}$ & $V_{a c}$ & $\begin{array}{c}i_{a}=\left(V_{d c}-2 e_{a}-\right. \\
\left.e_{b}-e_{c}\right) / \\
2(\mathrm{R}+\mathrm{Ldi} / \mathrm{dt})\end{array}$ & $\begin{array}{l}i_{b}=\left(-e_{b}-e_{a}\right) / \\
2(\mathrm{R}+\mathrm{Ldi} / \mathrm{dt})\end{array}$ & $\begin{array}{c}i_{c}=\left(V_{d c}-e_{a}-e_{c}\right) / \\
2(\mathrm{R}+\mathrm{Ldi} / \mathrm{dt})\end{array}$ \\
\hline $\mathrm{B}, \mathrm{C}$ & $V_{b c}$ & $\begin{array}{l}i_{a}=\left(-e_{a}-e_{c}\right) / \\
2(\mathrm{R}+\mathrm{Ldi} / \mathrm{dt})\end{array}$ & $\begin{array}{c}i_{b}=\left(V_{d c}-e_{b}-e_{c}\right) / \\
2(\mathrm{R}+\mathrm{Ldi} / \mathrm{dt})\end{array}$ & $\begin{array}{c}i_{c}=\left(V_{d c}-e_{a}-e_{b}-2\right. \\
\left.e_{c}\right) / \\
2(\mathrm{R}+\mathrm{Ldi} / \mathrm{dt})\end{array}$ \\
\hline $\mathrm{B}, \mathrm{A}$ & $V_{b a}$ & $\begin{array}{c}i_{a}=\left(V_{d c}-e_{a}-e_{b}\right. \\
) / \\
2(\mathrm{R}+\mathrm{Ldi} / \mathrm{dt})\end{array}$ & $\begin{array}{c}i_{b}=\left(V_{d c}-e_{a}-2 e_{b^{-}}\right. \\
\left.e_{c}\right) / \\
2(\mathrm{R}+\mathrm{Ldi} / \mathrm{dt})\end{array}$ & $\begin{array}{l}i_{c}=\left(-e_{b}-e_{c}\right) / \\
2(\mathrm{R}+\mathrm{Ldi} / \mathrm{dt})\end{array}$ \\
\hline C,A & $V_{c a}$ & $\begin{array}{c}i_{a}=\left(V_{d c}-2 e_{a}-\right. \\
\left.e_{b}-e_{c}\right) / \\
2(\mathrm{R}+\mathrm{Ldi} / \mathrm{dt})\end{array}$ & $\begin{array}{l}i_{b}=\left(-e_{b}-e_{a}\right) / \\
2(\mathrm{R}+\mathrm{Ldi} / \mathrm{dt})\end{array}$ & $\begin{array}{c}i_{c}=\left(V_{d c}-e_{c}-e_{a}\right) / \\
2(\mathrm{R}+\mathrm{Ldi} / \mathrm{dt})\end{array}$ \\
\hline C,B & $V_{c b}$ & $\begin{array}{l}i_{a}=\left(-e_{c}-e_{a}\right) / \\
2(\mathrm{R}+\mathrm{Ldi} / \mathrm{dt})\end{array}$ & $\begin{array}{c}i_{b}=\left(V_{d c}-e_{c}-e_{b}\right) / \\
2(\mathrm{R}+\mathrm{Ldi} / \mathrm{dt})\end{array}$ & $\begin{array}{c}i_{c}=\left(V_{d c}-e_{a}-e_{b}-2\right. \\
\left.e_{c}\right) / \\
2(\mathrm{R}+\mathrm{Ldi} / \mathrm{dt})\end{array}$ \\
\hline A,B & $V_{a b}$ & $\begin{array}{c}i_{a}=\left(V_{d c}-e_{a}-e_{b}\right. \\
) / \\
2(\mathrm{R}+\mathrm{Ldi} / \mathrm{dt})\end{array}$ & $\begin{array}{c}i_{b}=\left(V_{d c}-e_{a}-2 e_{b}-\right. \\
\left.e_{c}\right) / \\
2(\mathrm{R}+\mathrm{Ldi} / \mathrm{dt})\end{array}$ & $\begin{array}{l}i_{c}=\left(-e_{b}-e_{c}\right) / \\
2(\mathrm{R}+\mathrm{Ldi} / \mathrm{dt})\end{array}$ \\
\hline
\end{tabular}

In $120^{\circ}$ conduction mode of inverter, at each instant two phases will conduct; whereas the isolated phase current flows through freewheeling diodes. $V_{d 3}$ is The diode voltage required to keep the isolated phase current to remain at zero until the next switching takes place. This scenario can be explained with the help of circuit-1 as shown in figure 5 (a) The behaviour of the circuit can be expressed with the help of two conditions i.e. diode current $i_{3} \neq 0$ and $i_{3}=0$.

During diode current ' $i_{3}$ ' non zero condition $V_{a c}=+V_{d c}, V_{b c}=0, V_{c a}=-V_{d c}$. When diode current reaches zero the circuit behaviour explained in equations (22) to (24).

Circuit (1): During phase A \& C conduction:

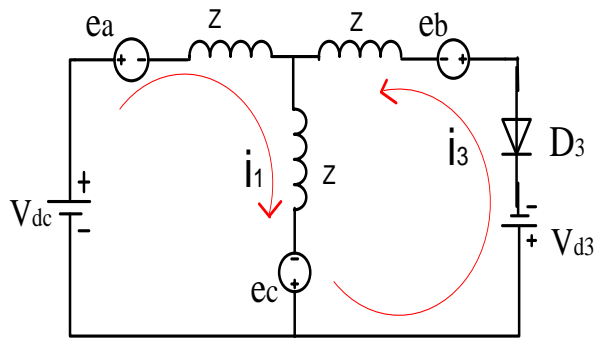

Figure.5 (a) circuit-1

From the above circuit (1):

$$
\begin{array}{ccc}
-V_{a c}+e_{a}+i_{1} \mathrm{Z}+\mathrm{Z}\left(i_{1}+i_{3}\right)-e_{c}=0 & \text { loop } & (1) \\
+e_{b}+i_{3} \mathrm{Z}+\mathrm{Z}\left(i_{1}+i_{3}\right)-e_{c}=0 & \text { loop } & \text { (2) }
\end{array}
$$

From loop (1)

$$
\begin{gathered}
-V_{a c}+e_{a}+\mathrm{Z}\left(i_{1}+i_{1}+i_{3}\right)-e_{c}=0 \\
\mathrm{Z}\left(2 i_{1}+i_{3}\right)=V_{a c}-e_{a}+e_{c} \\
\mathrm{Z}=V_{a c}-e_{a}+e_{c} /\left(2 i_{1}+i_{3}\right)
\end{gathered}
$$

Substitute $\mathrm{Z}$ value in loop (2) in order to get $V_{d 3}$

$$
\left.\begin{array}{c}
V_{d 3}+e_{b}+\mathrm{Z}\left(i_{1}+i_{3}+i_{3}\right)-e_{c}=0 \\
V_{d 3}+e_{b}+\mathrm{Z}\left(i_{1}+2 i_{3}\right)-e_{c}=0
\end{array}\right\}
$$

When $i_{3}=0$; the freewheeling diode supports voltage $\mathrm{V}_{\mathrm{d} 3}$ in order to keep the phase current remain at zero until next interval starts. Using Equations 22 and 24 the diode blocking voltage $\mathrm{V}_{\mathrm{d} 3}$ is obtained as follows.

$$
\left.\begin{array}{c}
V_{d 3}+e_{b}+\frac{V_{a c}-e_{a}+e_{c}}{2 i_{1}+i_{3}}\left(i_{1}+2 i_{3}\right)-e_{c}=0 \\
V_{d 3}+e_{b}+\left(V_{a c}-e_{a}+\frac{e_{c}}{2}\right)-e_{c}=0 \\
\left(\text { since } i_{3}=0\right. \\
V_{d 3}+e_{b}+V_{a c} / 2-e_{a} / 2-e_{c} / 2=0 \\
V_{d 3}=-e_{b}-\frac{V_{a c}}{2}-\frac{e_{a}}{2}-\frac{e_{c}}{2}=0 \\
V_{d 3}=1 / 2\left(-V_{a c}+e_{a}+e_{c}-2 e_{b}\right)
\end{array}\right\}
$$

Circuit (2): During phase B \& C conduction:

When diode current non zero i.e. $i_{3} \neq 0$, the phase to phase voltages expressed as

$V_{c b}=-V_{d c}, V_{a b}=0, V_{b c}=+V_{d c}$

Published By: 


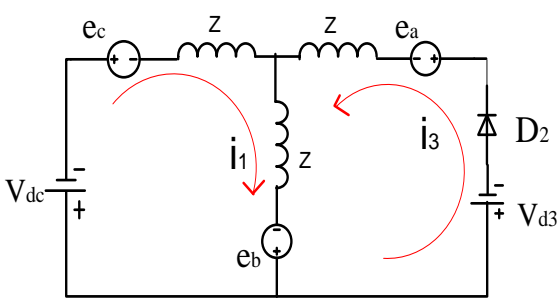

Figure.5 (b) circuit-2

From circuit-2:

$$
\begin{array}{ll}
V_{c b}+e_{c}+i_{1} \mathrm{Z}+\mathrm{Z}\left(i_{1}+i_{3}\right)-e_{b}=0 & \text { loop } \\
V_{d 3}+e_{a}+i_{3} \mathrm{Z}+\mathrm{Z}\left(i_{3}+i_{1}\right)-e_{b}=0 & \text { loop }
\end{array}
$$

From loop (1)

$$
\left.\begin{array}{c}
V_{c b}+e_{c}+\mathrm{Z}\left(i_{1}+i_{1}+i_{3}\right)-e_{b}=0 \\
\mathrm{Z}\left(2 i_{1}+i_{3}\right)=-V_{c b}-e_{c}+e_{b} \\
\mathrm{Z}=-V_{c b}-e_{c}+e_{b} /\left(2 i_{1}+i_{3}\right.
\end{array}\right\}
$$

Substitute $\mathrm{Z}$ value in loop (2) in order to get $V_{d 3}$

$$
\left.\begin{array}{c}
V_{d 3}+e_{a}+\mathrm{Z}\left(i_{1}+i_{3}+i_{3}\right)-e_{b}=0 \\
V_{d 3}+e_{a}+\mathrm{Z}\left(i_{1}+2 i_{3}\right)-e_{b}=0 \\
V_{d 3}+e_{a}+\frac{-V_{c b}-e_{c}+e_{b}}{2 i_{1}+i_{3}} \cdot\left(i_{1}+2 i_{3}\right)-e_{b}=0 \\
V_{d 3}+e_{a}+\left(-V_{c b}-e_{c}+\frac{e_{b}}{2}\right)-e_{b}=0 \\
\left(\operatorname{since} i_{3}=0\right) \\
V_{d 3}+e_{a}-\frac{V_{c b}}{2}-\frac{e_{c}}{2}-\frac{e_{b}}{2}=0 \\
V_{d 3}=-e_{a}+V_{c b}+\frac{e_{c}}{2}+\frac{e_{b}}{2} \\
V_{d 3}=1 / 2\left(V_{c b}+e_{c}+e_{b}-2 e_{a}\right)
\end{array}\right\}
$$

\begin{tabular}{|c|c|c|}
\hline $\begin{array}{c}\begin{array}{c}\text { Conducting } \\
\text { phases }\end{array} \\
\end{array}$ & Impedance & Diode voltages \\
\hline AC & $\mathrm{Z}=V_{a c}-e_{a}+e_{c} /\left(2 i_{1}+i_{3}\right)$ & $\begin{array}{c}V_{d 3}= \\
1 / 2\left(-V_{a c}+e_{a}+e_{c}-2 e_{b}\right)\end{array}$ \\
\hline $\mathrm{BC}$ & $\mathrm{Z}=-V_{c b}-e_{c}+e_{b} /\left(2 i_{1}+i_{3}\right)$ & $\begin{array}{c}V_{d 3}= \\
1 / 2\left(V_{c b}+e_{c}+e_{b}-2 e_{a}\right)\end{array}$ \\
\hline BA & $\mathrm{Z}=V_{b a}-e_{b}+e_{a} /\left(2 i_{1}+i_{3}\right)$ & $\begin{array}{c}V_{d 3}= \\
1 / 2\left(-V_{b a}+e_{b}+e_{a}-2 e_{c}\right)\end{array}$ \\
\hline CA & $\mathrm{Z}=-V_{c a}-e_{c}+e_{a} /\left(2 i_{1}+i_{3}\right)$ & $\begin{array}{c}V_{d 3}= \\
1 / 2\left(V_{c a}+e_{c}+e_{a}-2 e_{b}\right)\end{array}$ \\
\hline CB & $\mathrm{Z}=V_{c b}-e_{c}+e_{b} /\left(2 i_{1}+i_{3}\right)$ & $\begin{array}{c}V_{d 3}= \\
1 / 2\left(-V_{c b}+e_{c}+e_{b}-2 e_{a}\right)\end{array}$ \\
\hline & $\mathrm{Z}=$ & $V_{d 3}=$ \\
\hline
\end{tabular}

Similar equations can be obtained for the other conduction sequences.

Values for $\mathrm{Z}$ and $\mathrm{Vd} 3$ are given in the following table.

Table-2 Line impedance and diode voltages during freewheeling condition

\section{A . CONTROLTECHNIQUE OF PROPOSED METHOD}

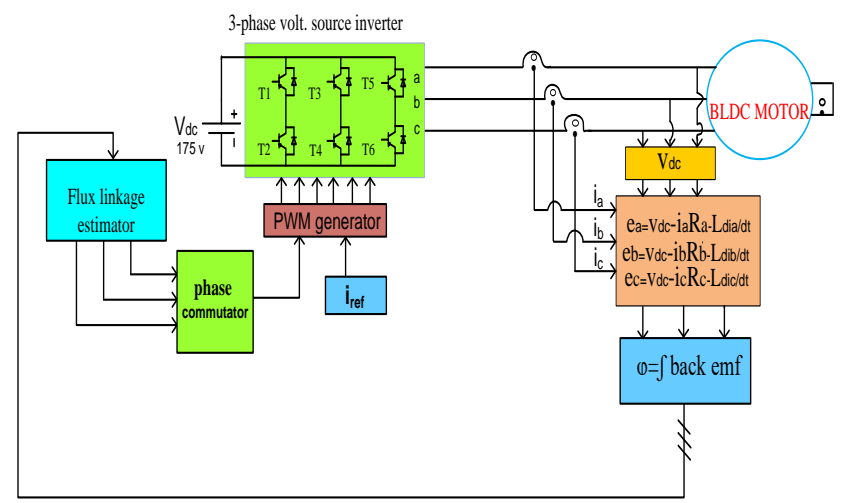

Figure.6 Control Circuit Diagram of Flux Linkage Based Sensorless BLDC Motor

Line Voltages $\left(V_{L}\right)$ and phase currents $\left(i_{a}\right)$ are the main parameters for back emf calculations which are tapped from the BLDC motor input terminals this $\mathrm{V}$, I are used in back emf calculation. Back emf $E$ is expressed as $E=V-I R-$ $L \frac{d i}{d t}$. This back-emf may also be written as rate of change of flux linkages i.e. $\mathrm{E}=\frac{d \varphi}{d t}$. From above two statements $\mathrm{E}$ can be written as $\mathrm{E}=\frac{d \varphi}{d t}=V_{L}-I_{a} R_{a}-L \frac{d i_{a}}{d t}$. In order to get the individual phase flux linkages $\left(\psi_{a}, \psi_{b}, \psi_{c}\right)$ integrate the back emf equation which is expressed in equation (28) since two phase mode of operation has been considered here, for the back emf calculation the line voltage $\left(V_{L}\right)$, resistance of two phases (2R) and inductance of two phases (2L) have to be considered and while performing integration of this back emf proper initial conditions have been taken. The schematic control circuit diagram is shown in figure 6 . The present analysis is confined to open loop control performance of the motor since the main purpose is to test the correctness of the proposed switching algorithm based on Phase Flux Linkages .So the Iref in Fig. 6 is constant and its value is obtained from the desired developed torque.

$$
\varphi=\int V_{L}-2 I_{a} R_{a}-2 L \frac{d i_{a}}{d t}
$$

Inverter switching states based on the three phase flux linkage values are given in Table-3 
TABLE- 3 INVERTER SWITCHING SEQUENCE

$\left(T_{1} T_{3} T_{5}\right.$ and $T_{2} T_{4} T_{6}$ are the upper leg switches and lower leg switches of inverter)

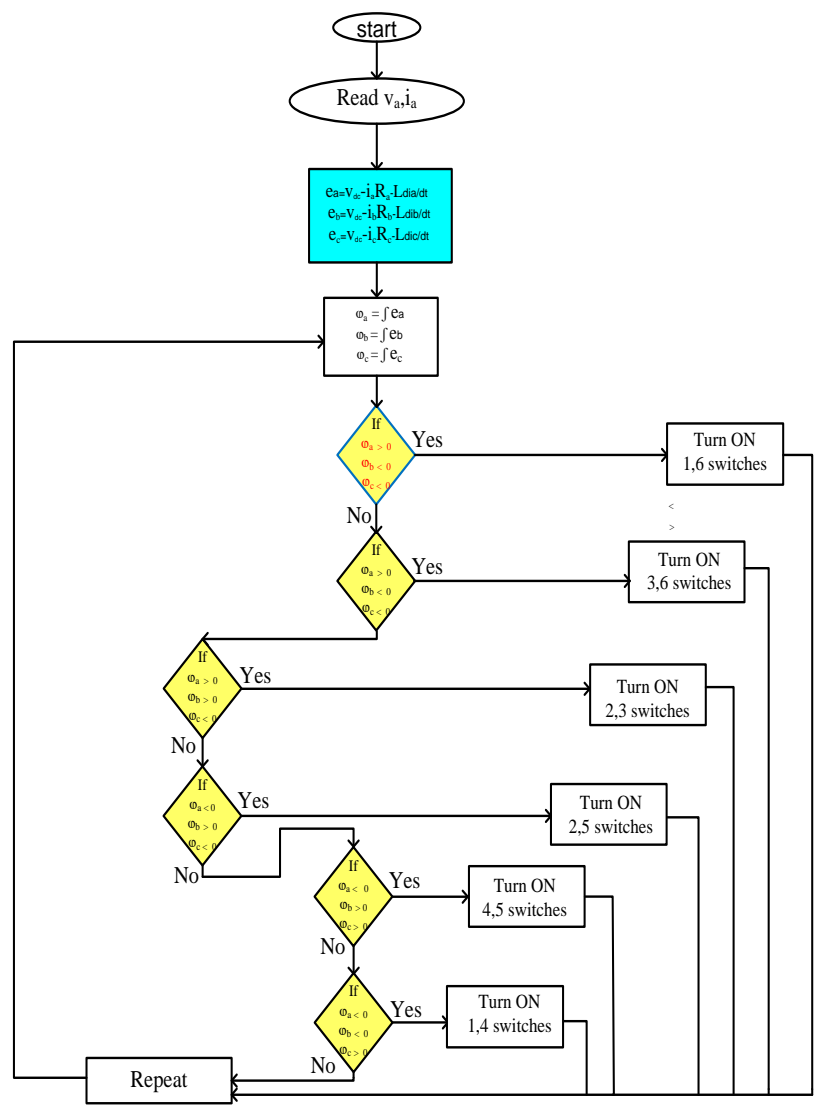

Figure .7 Flow chart diagrams for the proposed sensorless control algorithm

B. COMPUTATION OF PHASE CURRENTS

In conventional method the switching of the inverter depends on rotor position, whereas in proposed method the switching is a function of flux linkages. For the first switching, phase A switch- $\mathrm{T}_{1}$ and phase $\mathrm{C}$ switch- $\mathrm{T}_{6}$ turns $\mathrm{ON}$. The magnitudes of two phases are equal but their polarities are opposite. From the inverter configuration positive current flows through upper switches and negative current flows through lower switches via phase windings.

$$
\text { So, } i_{a}=-i_{c}
$$

During this state of conduction switches $T_{1}, T_{6}$ are $O N$, current flows through $+V_{d c}-T_{1}$-a-c- $T_{6}--V_{d c}$. The phase current is $i_{a}(\mathrm{t})=-i_{c}(\mathrm{t})=\left(\left(V_{d c}-2 e_{b}\right) / 2 \mathrm{R}\right)\left(1-e^{-\frac{R}{L} \cdot t}\right)$.This mode exists when the flux linkages $\psi_{a}>0, \psi_{b}<0, \psi_{c}>0$. The phase current will be limited when $i_{a}$ reaches reference current $i_{\text {ref }}$ $\left(i_{a}=-i_{c}=i_{\text {ref }}\right)$ and it will continue up to the next condition $\left(\psi_{a}>0, \psi_{b}<0, \psi_{c}<0\right)$. When $\psi_{a}>0, \psi_{b}<0, \psi_{c}<0$ Phase B switch $\mathrm{T}_{3}$ will be $\mathrm{ON}$ and the phase-A switch $\mathrm{T}_{1}$ will be OFF. Since phase A current cannot reach zero current instantly this drooping current freewheels through a-c- $T_{6}-\mathrm{D}_{2}$ -a. During this freewheeling period the phase A current can be expressed as

$\left.i_{a}(t)=\left(I_{0}+\frac{2 e_{b}+I_{0} R}{R}\right) e^{-\frac{R}{L} \cdot t}-\frac{2 e_{b}+I_{0} R}{R}\right\}$

The equation (29) is valid up to $i_{a}(t)$ value reaches zero. At the same time phase $B$ current rises from zero, this can be expressed as

$\left.i_{b}(t)=\left(\frac{2 e_{b}+I_{0} R-V_{d c}}{R}\right) e^{-\frac{R}{L} \cdot t}+\frac{V_{d c}-2 e_{b}+I_{0} R}{R}\right\}$
Similarly $i_{b}(t)$ increases up to $i_{\text {ref }}$ and continue to flow until next sequential switching takes place. During this mode of operation the phase $\mathrm{C}$ current remains unchanged and its value is derived from KCL equation

$$
i_{c}=-i_{a}-i_{b}
$$

\begin{tabular}{|c|c|c|c|c|c|c|c|c|}
\hline \multicolumn{3}{|c|}{$\begin{array}{c}\text { Phase flux } \\
\text { linkages(we } \\
\text { b-turns) }\end{array}$} & \multicolumn{6}{|c|}{ Inverter switching sequence } \\
\hline$\psi_{a}$ & $\psi_{b}$ & $\psi_{c}$ & $T_{1}$ & $T_{2}$ & $T_{3}$ & $T_{4}$ & $T_{5}$ & $T_{6}$ \\
\hline $\begin{array}{l}> \\
0 \\
\end{array}$ & $\begin{array}{l}< \\
0 \\
\end{array}$ & $\begin{array}{l}> \\
0\end{array}$ & $\mathrm{ON}$ & OFF & OFF & OFF & $\begin{array}{c}\text { OF } \\
\text { F }\end{array}$ & ON \\
\hline $\begin{array}{l}> \\
0\end{array}$ & $\begin{array}{l}< \\
0\end{array}$ & $\begin{array}{l}< \\
0 \\
\end{array}$ & $\begin{array}{c}\text { OF } \\
\text { F }\end{array}$ & OFF & ON & OFF & $\begin{array}{c}\text { OF } \\
F\end{array}$ & $\mathrm{ON}$ \\
\hline $\begin{array}{l}> \\
0 \\
\end{array}$ & $\begin{array}{l}> \\
0 \\
\end{array}$ & $\begin{array}{l}< \\
0 \\
\end{array}$ & $\begin{array}{c}\text { OF } \\
\text { F }\end{array}$ & ON & ON & OFF & $\begin{array}{c}\mathrm{OF} \\
\mathrm{F}\end{array}$ & OFF \\
\hline $\begin{array}{l}< \\
0 \\
\end{array}$ & $\begin{array}{l}> \\
0\end{array}$ & $\begin{array}{l}< \\
0\end{array}$ & $\begin{array}{c}\mathrm{OF} \\
\mathrm{F}\end{array}$ & $\mathrm{ON}$ & OFF & OFF & $\mathrm{ON}$ & OFF \\
\hline $\begin{array}{l}< \\
0 \\
\end{array}$ & $\begin{array}{l}> \\
0\end{array}$ & $\begin{array}{l}> \\
0 \\
\end{array}$ & $\begin{array}{c}\text { OF } \\
\text { F }\end{array}$ & OFF & OFF & ON & $\mathrm{ON}$ & OFF \\
\hline $\begin{array}{l}< \\
0 \\
\end{array}$ & $\begin{array}{l}< \\
0\end{array}$ & $\begin{array}{l}> \\
0\end{array}$ & ON & OFF & OFF & $\mathrm{ON}$ & $\begin{array}{c}\text { OF } \\
\text { F }\end{array}$ & OFF \\
\hline
\end{tabular}

While calculating phase currents two times of back emf and

one time of $L \frac{d i_{a}}{d t}$ drop was considered since the current in the already conducting phase will remain fairly constant and its rate of change is zero. The simulation results of Phase currents $i_{a}, i_{b}, i_{c}$ are shown in figure 8 (a) to 8 (c).

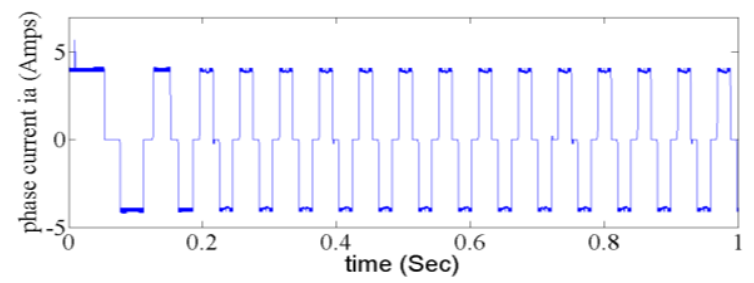

Figure 8(a) simulated wave form of phase A current (amps)

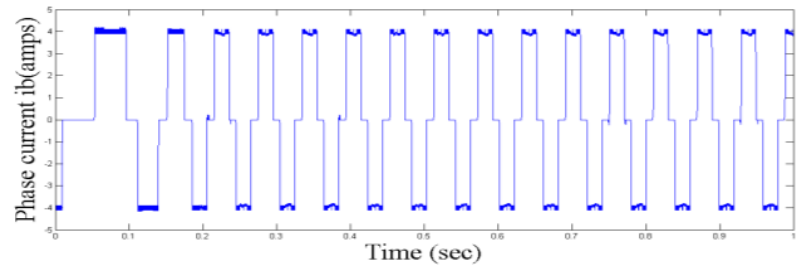

Figure 8 (b) simulated wave form of phase B current (amps)

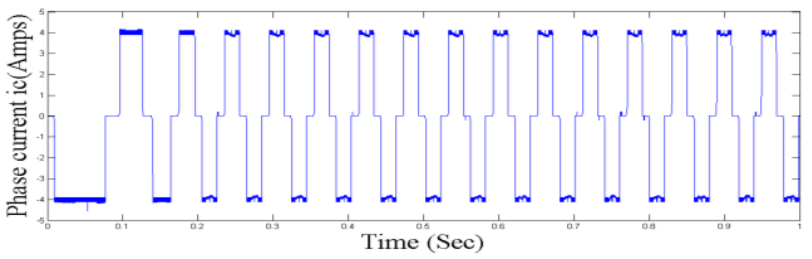

Figure 8(c) simulated wave form of phase $C$ currents (amps)

Published By:

Blue Eyes Intelligence Engineering \& Sciences Publication 
Motor parameters and specifications are given in Table-4.

\begin{tabular}{|lc|l|}
\hline \multicolumn{2}{|c|}{ Parameter and its symbol } & \multicolumn{1}{c|}{ Value } \\
\hline & & \\
Resistance per phase & $\mathrm{R}$ & $0.8 \mathrm{ohm}$ 's \\
Inductance per phase & $\mathrm{L}$ & $4.5 \mathrm{mH}$ \\
Load torque & $T_{l}$ & $12.5 \mathrm{Nm}$ \\
Moment of inertia & $\mathrm{J}$ & $0.00208 \mathrm{~kg}-\mathrm{m}^{2}$ \\
Damping co-efficient & $\mathrm{B}$ & $0.005 \mathrm{~N}-\mathrm{m} / \mathrm{rad} / \mathrm{sec}$ \\
Peakvalue of rated current & $\mathrm{A}$ & $5 \mathrm{Amp}$ \\
Rated voltage & $\mathrm{V}$ & $175 \mathrm{volts}$ \\
No.of poles & $\mathrm{P}$ & 4 \\
\hline
\end{tabular}

(Mutual inductance between phases is assumed to be half of phase self-inductance)

\section{RESULTS}

A 3-phase sensorless BLDC motor is mathematically modelled, simulation done for proposed controlling technique. The line voltages $\mathrm{V}_{\mathrm{ac}}, \mathrm{V}_{\mathrm{cb}}$ are shown in figure 9 (a) \& 9 (b). Phase back emf's are shown in fig.10 (a) to 10(c), flux linkage values are obtained by integrating the phase back-emf's generated inside the motor, and the developed flux linkages are triangular in shape. This is shown in Figure 11. In addition the combination of phase current, back emf and flux linkages are shown in Figure 12(a) to 12(c) Speed and torque curves are shown in Figure 13, Figure.14, The flux linkages logics was described with the help of flow chart which is shown in figure.7 The proposed technique tested for no load and constant speed conditions through mat lab. In order to find the accuracy of this flux estimation switching technique this method was compared with Hall Effect sensor controlled switching BLDC drive.

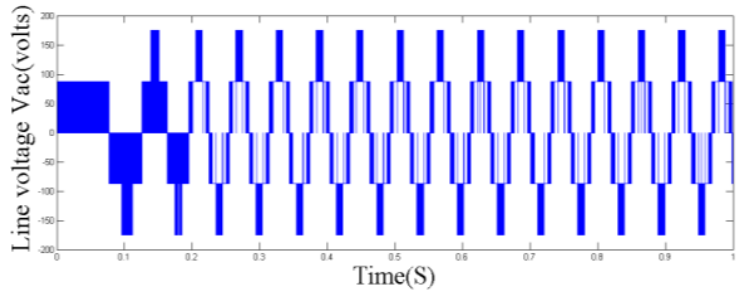

Figure 9 (a) simulated wave form of phase to phase voltage $V_{a c}$ (volts)

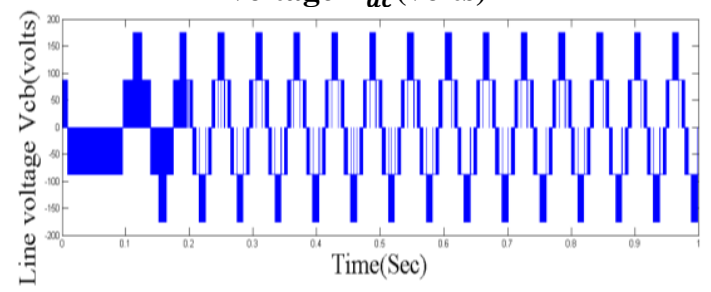

Figure 9 (b) simulated wave form of phase to phase voltage $V_{c b}$ (volts)

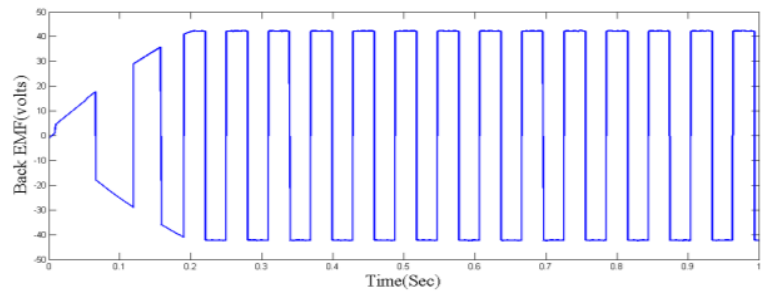

Figure 10 (a) simulated wave form of phase A back emf (volts)

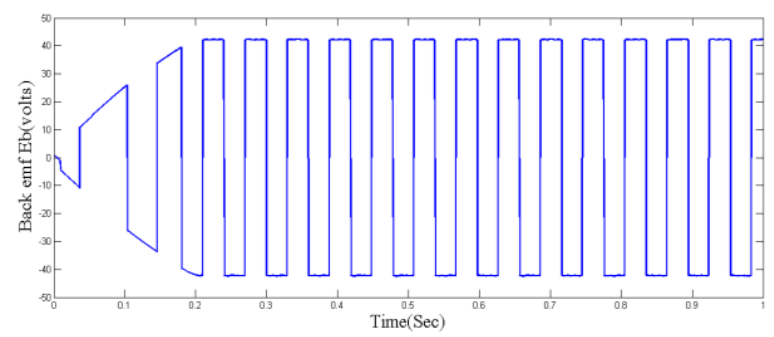

Figure 10 (b) simulated wave form of phase B back emf (volts)

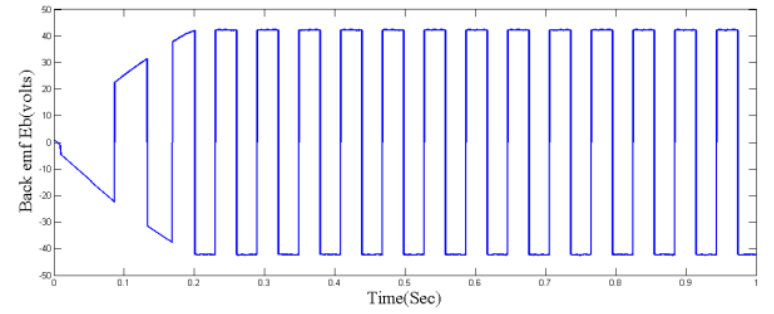

Figure 10 (c) simulated wave form of phase C back emf (volts)

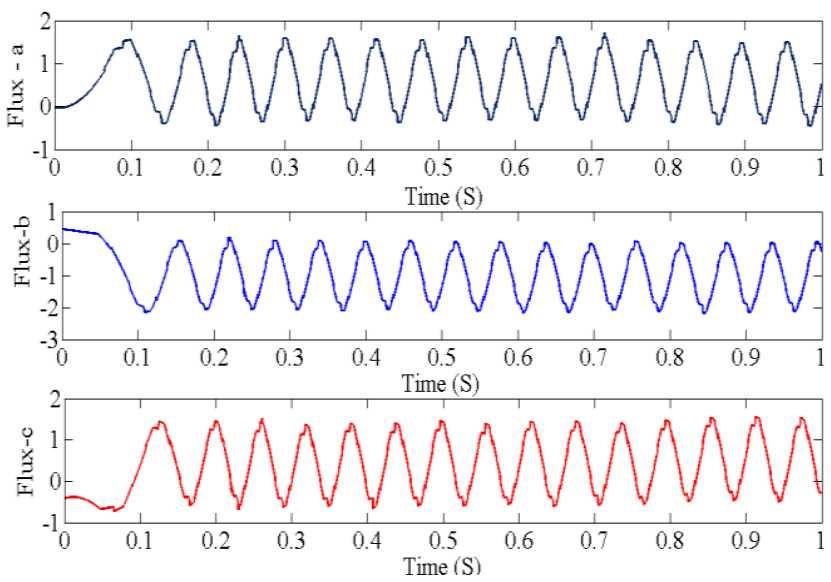

Figure (11) simulated wave form of 3-phase flux linkages $\psi_{a}, \psi_{b}, \psi_{c}$ in (webers)

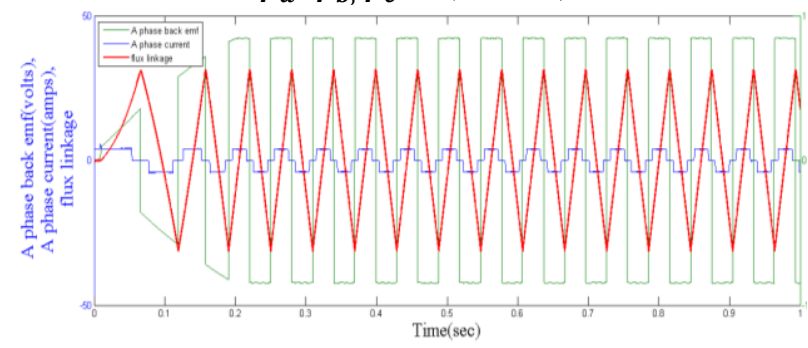

Figure 12 (a) phase ' $A$ ' back emf (volts), phase current $I_{b}$ (amps), flux linkages $\psi_{a}$ (webers)

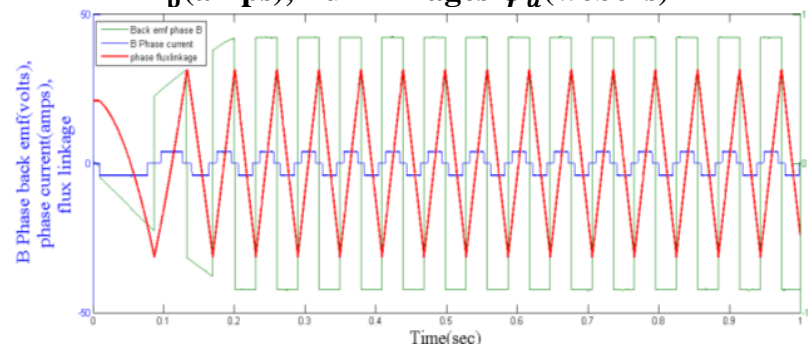

Figure 12 (b) phase ' $B$ ' back emf (volts), phase current $I_{b}$ (amps), flux linkages $\psi_{b}$ (webers)

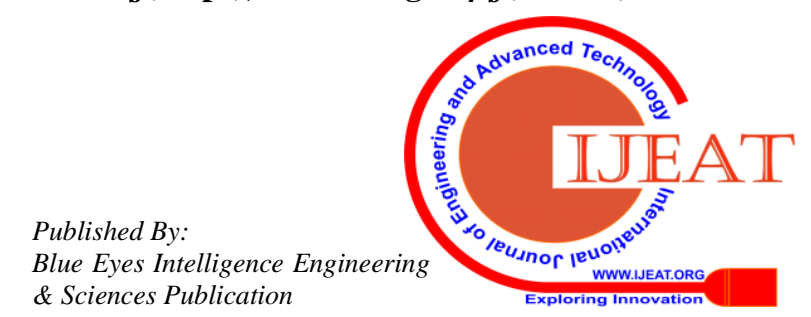




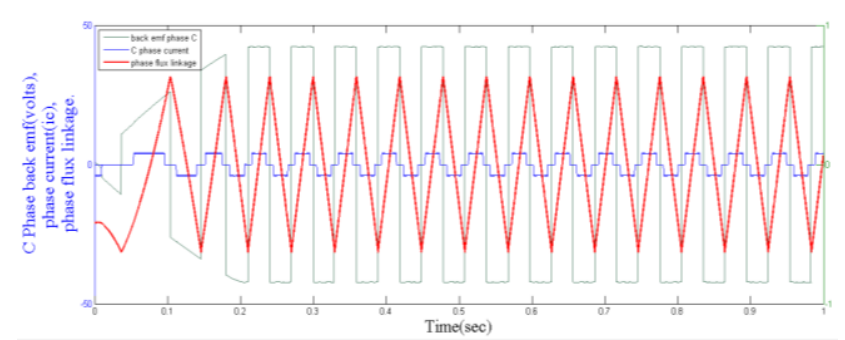

Figure 12 (c) phase ' $C$ ' back emf (volts), phase current $I_{c}$ (amps), flux linkages $\psi_{c}$ (webers)

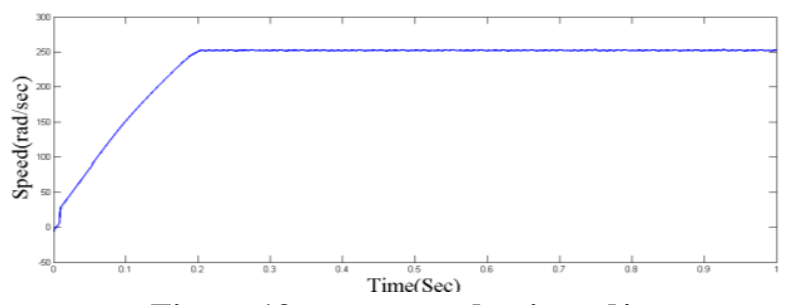

Figure.13 motor speed $\omega$ in $\mathrm{rad} / \mathrm{sec}$

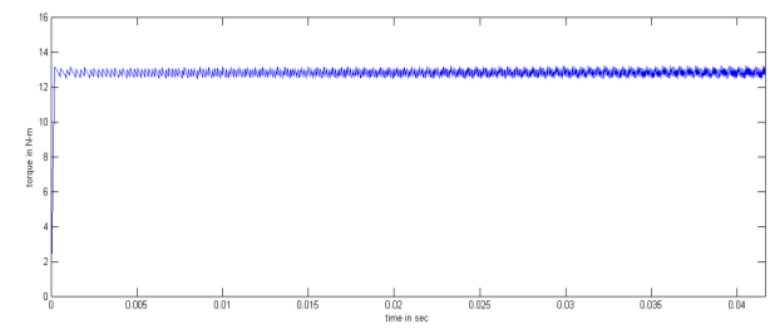

Figure.14 simulation result of torque curve in $\mathrm{N}-\mathrm{m}$

\section{CONCLUSIONS}

Sensorless back EMF detection and integration techniques have a drawback during starting period of the motor. In back emf detection control method the machine cannot develop back emf $\left(E_{b}\right)$ accuratly at starting, since $\left(\mathrm{E}_{\mathrm{b}}=\mathrm{k} . \omega\right)$ back emf is speed $(\omega)$ dependent function. This drawback would be overcome by this flux linkage estimation technique which is speed independent function. This flux linkage function was derived in equation (28). With the help of this 3-phase flux linkage values based algorithm, switching sequence of the inverter is controlled at any speed range accurately. The proposed algorithm has following features that it is very simple to understand, by eliminating robust electronic arrangement for position estimation accuracy of system controlling improves. This technique can work accurately at all whether conditions. With all above discussed features BLDC motors can be the most preferable drive compare to all other synchronous and asynchronous machines in industrial as well agricultural applications.

\section{REFERENCES}

1. José Carlos Gamazo-Real, Ernesto Vázquez-Sánchez and Jaime Gómez-Gil "Position and Speed Control of Brushless DC Motors Using Sensorless Techniques and Application Trends", Sensors 19 July 2010. 6901-6947.

2. James P. Johnson, M. Ehsani, Yilcan Giizelgiinler "Review of sensorless methods for brushless DC" Industry Applications Conference, 1999. IEEE ISSN: 0197-2618.

3. José Carlos Gamazo-Real *, Ernesto Vázquez-Sánchez and Jaime Gómez-Gil "Position and Speed Control of Brushless DC Motors Using Sensorless Techniques and Application Trends".

4. Damodharan,P, Vasudevan K. "Indirect Back-EMF Zero Crossing Detection for Sensorless BLDC Motor Operation". In Proceedings of the International Conference on Power Electronics and Drives
Systems (PEDS 2005), Kuala Lumpur, Malaysia, November 2008; pp. 1107-1111.

5. Gui-Jia Su and John W. McKeever "Low-Cost Sensorless Control of Brushless DC Motors With Improved Speed Range” IEEE transactions on power electronics, vol. 19, no. 2, march 2004.

6. Alfio Consoli, Salvatore Musumeci."Sensorless Vector and Speed Control of Brushless Motor Drives". IEEE transactions on industrial electronics, vol. 41, no.1, February 1994.

7. Protik Chandra, Biswas and Bashudeb Chandra Ghosh "A Novel Flux Estimation Algorithm Based Position Sensorless Field Oriented Vector Controlled Permanent Magnet Brushless DC Motor Drive". IEEE $3^{\text {rd }}$ International Conference on Electrical Information and Communication Technology (EICT) 2017.

8. Tae-Hyung Kim, " sensor less control of the bldc motors from near-zero to high speeds". IEEE transactions on power electronics, vol. 19, no. 6, November 2004

9. Nobuyuki Matsui, "sensorless pm brushless dc motor drive" IEEE transactions on industrial electronics, vol. 43, no 2, April 1996.

10. wook-jin lee, seung-ki sul, "a new starting method of bldc motors without position sensor". IEEE transactions on industry applications, vol. 42, no. 6, November/December 2006.

11. Cassio Luciano Baratieri, and Humberto Pinheiro. "An i-f starting method for smooth and fast transition to sensorless control of bldc motors". IEEE Conference June 2013.

12. C. Cui, G. Liu, K. Wang, and X. Song, "Sensorless drive for high speed brushless DC motor based on the virtual neutral voltage," IEEE Trans. Power. Electron., vol.30, no. 6, Jun. 2015.

13. J. X. Shen and S. Iwasaki, "Sensorless control of ultrahigh-speed PM brushless motor using PLL and third harmonic back EMF," IEEE Trans. Ind. Electron., vol. 53, no.2, Apr. 2006.

14. Stefan Baldursson, "BLDC motor modelling and control- a MATLAB / SIMULINK implementation", Master Thesis in Electrical Power Engineering, Chalmers University of Technology, May 2005, Gothenburg, Sweden.

15. Padmaraja Yedamale, "Brushless DC (BLDC) Motor Fundamentals Application” Note; AN885, Microchip: AZ, USA. 2003. 